E. M. CARREIRA*,A. FRANK* ET AL. (EIDGENÖSSISCHE TECHNISCHE HOCHSCHULE ZÜRICH, SWITZERLAND AND OREGON HEALTH \& SCIENCE UNIVERSITY, PORTLAND, US A )

Optical Control of Cannabinoid Receptor 2-Mediated $\mathrm{Ca}^{2+}$ Release Enabled by Synthesis of Photoswitchable Probes J. Am. Chem. Soc. 2021, 143, 736-743, DOI: 10.1021/jacs.0c08926.

\section{Optical Control of the Cannabinoid Receptor 2}
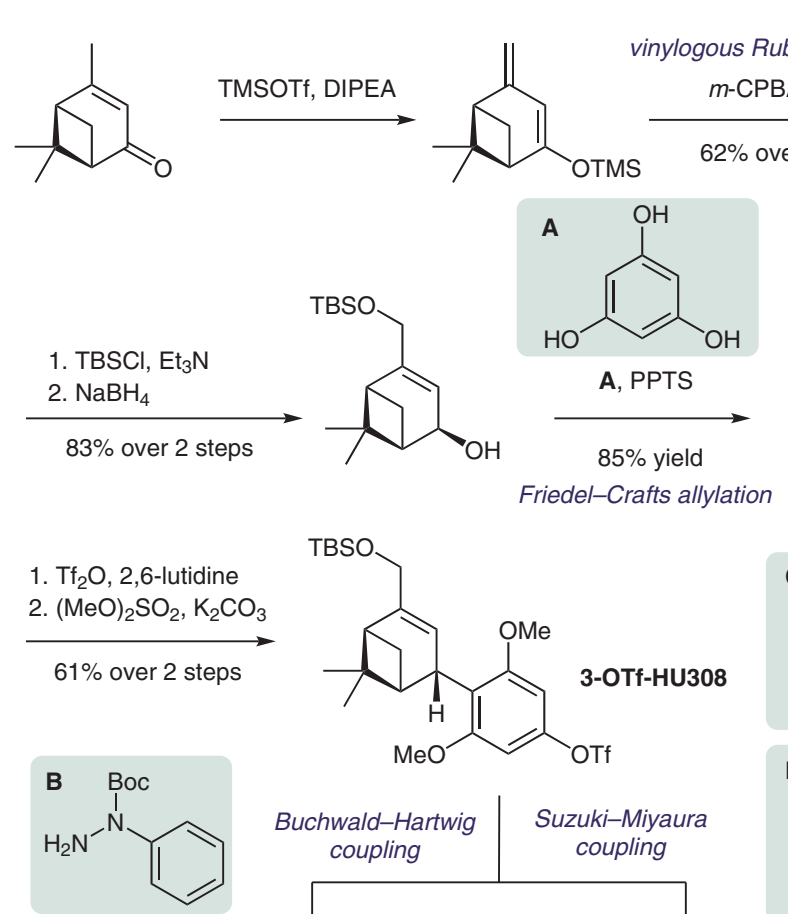

1. B, $\mathrm{Pd}(\mathrm{OAC})_{2}$,

$t-\mathrm{Bu}_{3} \mathrm{PHBF}_{4}, \mathrm{Cs}_{2} \mathrm{CO}_{3}$

2. air, $\mathrm{NaHCO}_{3}$

3. TBAF

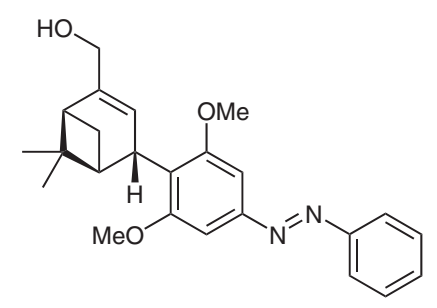

azo-HU308-1 (77\% over 3 steps)
Category

Chemistry in

Medicine and

Biology

\section{Key words}

G protein-coupled receptors

photoswitches

azobenzenes
Significance: Cannabinoid receptor 2 (CB2) is a C protein-coupled receptor with important roles in immunobiology. Pharmacological regulation holds promise for the treatment of neurological disorders. Photoswitchable probes would offer high spatiotemporal control, leading to new insights into CB2 signaling. The Carreira and Frank groups describe the development of azo-HU308-3, a probe that is inactive in the dark and can be activated upon irradiation with $375 \mathrm{~nm}$ light.
Comment: A series of three HU308-derived photoswitches (azo-HU308-1-3) were synthesized from the terpene (+)-verbenone. 3-0Tf-Hu308 could be accessed in seven robust and high-yielding steps. Azobenzene photoswitches were attached to this intermediate using Buchwald-Hartwig or SuzukiMiyaura couplings with potassium trifluoroborate reagents $\mathbf{C}$ and $\mathbf{D}$ as pioneered by Molander (Synlett 2005, 1763). 